\title{
Inequalities in COVID-19 Research from Sub- Saharan Africa: Differences in the Prestige of Journal Articles with Internal and External Lead Authors, Collaborations and Publishers
}

\author{
Toluwase Victor Asubiaro ( $\nabla$ tasubiar@uwo.ca ) \\ University of Western Ontario https://orcid.org/0000-0003-0718-7739
}

\section{Research Article}

Keywords: COVID-19, Sub-Saharan Africa, research collaboration, international collaboration, research funding, bibliometric analysis

Posted Date: November 22nd, 2021

DOI: https://doi.org/10.21203/rs.3.rs-1032285/v1

License: (c) (1) This work is licensed under a Creative Commons Attribution 4.0 International License. Read Full License 


\section{Abstract}

Inequality in health research in Sub-Saharan Africa existed before the onset of the COVID-19 pandemic because of the dearth of research resources. The onset of COVID-19 has exacerbated inequality because of the changes in workplace settings. This study presents an insight into the extent of inequalities during the first year of COVID-19 using citation data of Sub-Saharan African countries' COVID-19 research. Citation data of all the 46 Sub-Saharan Africa countries was collected from Scopus, Web of Science and PubMed. After data cleaning and removal of duplicate records, collaboration type and publishers' country information was coded. Author processing charges of the Open Access articles were obtained from publishers' websites. CiteScore data was collected using Publish or Perish software and Scopus CiteScore report. Only $13.4 \%$ of the publishers are in Sub-Saharan African countries, and $21.14 \%$ of the articles were published in Sub-Saharan African journals. USA (20.92\%) and the UK (13.73\%), and India (6.21\%) house the highest number of publishers. Publishers from the Netherlands (30.72\%), the UK (24.23\%) and the USA (14.81\%) published the highest number of journals. The CiteScore of journals and mega journals published outside Sub-Saharan Africa was five and twenty-five times more prestigious than those published in the region, respectively. More equitable research practices that will recognize local authors from Sub-Saharan Africa as lead authors in studies about or in Sub-Saharan Africa and journals that are published in the region as a choice for important research may reduce the imbalances as observed in this study.

\section{Introduction}

Inequalities in science is a growing challenge, as the representation of persons based on gender (Bendels et al. 2017; Broderick \& Casadevall 2019; Huang et al. 2020), discipline (Holman et al. 2018; Huang et al. 2020) and regions (Hedt-Gauthier et al. 2019) is skewed representation. Researchers have registered their concerns about the increase in or existence of research equalities during the COVID-19 pandemic. For instance, (King \& Frederickson 2021; Muric et al. 2021; Pinho-Gomes et al. 2020) reported underrepresentation of women in the authorship, first and last authorship positions of COVID-19 publications. While productivity increased by $35 \%$ in the 10 weeks after the lockdown in the United States, the productivity of female academics' dropped by 13.2 per cent relative to that of their male counterparts (Cui et al. 2021). According to (Parlak et al. 2021) gender roles of females in the family has affected the productivity of female researchers during the pandemic, with females with children affected more (Staniscuaski et al. 2021), furthering the inequality among researchers.

Like gender inequality that is against women, previous studies have shown that Sub-Saharan Africa is also under-represented in research. While Sub-Saharan Africa accounts for $17.5 \%$ of the world's population, it produced only $2.6 \%$ of the world's science. Though research productivity to the gross domestic product from Africa has continued to increase faster than the world's average since 2003 (Confraria \& Godinho 2015; Pouris \& Ho 2014), there is evidence that there is a dearth of research resources in Sub-Saharan Africa which has continued to deepen low research productivity in the region. Therefore, researchers in Sub-Saharan Africa, like their peers in other low-income countries, collaborate 
with peers in high-income countries. For instance, researchers in Ghana were found to be motivated to collaborate with peers outside Africa by the prospect of funding (Owusu-Nimo \& Boshoff 2017). This has led to the dominance of research in Sub-Saharan Africa by foreign countries and the reliance of SubSaharan Africa on foreign countries. Collaboration with foreign countries usually account for about $50 \%$ of research in Africa, while less than $5 \%$ of the publications are products of collaboration between SubSaharan African countries; more emphasis has been placed on collaborating with foreign countries with little intra-Sub-Saharan African collaboration (Asubiaro 2019; Asubiaro \& Badmus 2020; Onyancha 2020; Onyancha \& Maluleka 2011).

Sub-Saharan African countries rely majorly on funding from foreign countries, and it has been reported that many research projects that are funded by the foreign countries fail because some Sub-Saharan African governments fail to show commitment with the payment of counterpart funding which is usually a fraction of the fund being provided by foreign countries (Bendana 2019). Also, it has been observed that international collaboration, which ordinarily is a measure of development, has led to "research neocolonialism" because of inequality in authorship against Sub-Saharan African researchers (Boshoff 2009; Hedt-Gauthier et al. 2019). Furthermore, publishers from Sub-Saharan Africa are under-represented in the major citation indexes (e.g. Scopus, Web of Science, PubMed, etc.). Hence, there is a fundamental bias against journals that are published in Sub-Saharan Africa, and this has led to the less visibility of these journals during research assessment since data from these major citation indexes are also used for assessing research visibility.

Research has shown that the challenges facing research development in Sub-Saharan Africa subsist in the COVID-19 research from the region. Sub-Saharan Africa research continues to rely on funding from foreign countries, and there is little (less than 5\%) intra-Sub-Saharan African collaboration, collaboration with foreign countries in more than 50\% of COVID-19 research (T. Asubiaro \& Shaik 2021). Gender inequality against women in research was found to be more pronounced in Africa than in other parts of the world during the COVID-19 pandemic (Pinho-Gomes et al. 2020).

The increase in the number of Gold Open Access (OA) articles (Laakso et al. 2011; Philipp et al. 2021) and journals is a good development because it helps build global equality in access to science. This development comes at a cost because of the introduction of the authors' processing charge, which is very expensive and not affordable by researchers in developing countries and young researchers. This OA authors' processing charge has caused a barrier in entrance into publishing in the elite journals by the young researchers and researchers from poor countries. There is no empirical evidence in the literature on the effect of the authors' processing charges on inequalities in science. Therefore, this study aims at investigating the inequalities in publications from Sub-Saharan Africa based on the differences in publications' prestige as influenced by author processing charges, publishers' location and collaboration type.

\section{Methodology}


COVID-19 research records of all the 46 Sub-Saharan African countries were retrieved from Scopus, MEDLINE and Web of Science databases. The search was done on Jan 12021 , to capture publications in 2020, with an update in April 2021, having noticed an increment in the number of publications in 2020. The search query was composed to retrieve publications on COVID-19 that were published by authors who are affiliated with institutions in Sub-Saharan Africa. The search query included the names of all the 46 countries in Sub-Saharan Africa. Variants of the Sub-Saharan African countries' names (e.g. Cameroun and Cameroon) were also included so that indexes with their variant names would be captured. All the variant names of COVID-19, as specified in peer-reviewed search strings of the Medical Library Association for bibliographic database retrieval of COVID-19 publications, were also included in the search query (LaLonde 2020). At the early stage of the COVID-19 pandemic, before the World Health Organization (WHO) assigned a globally recognized name, COVID-19 disease was called different names such as Wuhan coronavirus, Hubei coronavirus, China coronavirus, 2019 novel coronavirus disease, 2019-nCoV disease and Chinese Coronavirus, these names were included in our search query so that scientific publications that used such names were retrieved. Some of the names that were given to COVID-19 disease were later regarded as unethical because of their discriminatory tendencies. The search query implementation for retrieving Sub-Saharan Africa's publication from Scopus is as follows:

AFFILCOUNTRY ("South Africa" OR "Nigeria" OR "Angola" $O R$ "Benin" OR "Burkina Faso" OR "Burundi" OR "Cameroon" OR "Cameroun" OR "Canary Islands" OR "Cape Verde" OR "Central African Republic" $O R$ "Chad" $O R$ "Comoros" $O R$ "Congo" $O R$ "Democratic Republic of Congo" $O R$ "DR Congo" OR "Cote D'ivoire" $O R$ "ivory coast" $O R$ "Kenya" $O R$ "Lesotho" OR "Liberia" OR "Madagascar" OR "Malawi" OR "Mali" $O R$ "Mauritius" OR "Mozambique" $O R$ "Mocambique" OR "Namibia" $O R$ "Niger" OR "Principe" OR "Reunion" OR "Rwanda" OR "Sao Tome" OR "Senegal" OR "Seychelles" OR "Sierra Leone" $O R$ "Somalia" $O R$ "Sudan" $O R$ "Swaziland" $O R$ "Tanzania" OR "Togo" OR "Uganda" $O R$ "Zaire" $O R$ "Zambia" $O R$ "Zimbabwe" OR "South Sudan" OR "Ghana" OR "Ethiopia" OR "Eritrea" OR "Gambia" OR "Botswana" OR "Guinea" OR "Djibouti" OR "Gabon" OR "Papua and Guinea" OR "GuineaBissau" OR "Equatorial Guinea") AND TITLE-ABS-KEY ("2019 novel coronavirus disease" OR "COVID19" OR "COVID-19 pandemic" OR "SARS-CoV-2 infection" OR "COVID-19 virus disease" OR "2019 novel coronavirus infection" OR "2019-nCoV infection" OR "coronavirus disease 2019" OR "coronavirus disease-19" OR "2019-nCoV disease" OR "COVID-19 virus infection" OR "severe acute respiratory syndrome coronavirus 2" OR "COVID-19" OR "COVID19" OR "COVID2019" OR "SARSCoV2" OR "SARS coronavirus 2" OR "2019-nCoV" OR "2019nCoV" OR "nCoV2019" OR "nCoV-2019" OR "Wuhan coronavirus" $O R$ "Hubei coronavirus" $O R$ "chin* coronavirus")

A total of 2310 citations were retrieved from MEDLINE, 2400 citations were retrieved from Web of Science core collections, and 2830 citations were retrieved from Scopus. There were 3867 articles after data cleaning -removal of duplicates and errors (records with no Sub-Saharan African author).

Collaboration Types 
Four collaboration types were coded: single author or no collaboration, national, Sub-Saharan African, and international collaborations. Single author papers were classified as "no collaboration" papers. Papers by multiple authors who were affiliated with one or more institutions in a Sub-Saharan country were classified as national collaboration. Papers that were written by more than one author, who were affiliated to multiple institutions, where the institutions are located in multiple Sub-Saharan African countries and no author from institutions outside Sub-Saharan Africa were classified as Sub-Saharan African collaboration. National and international collaborations were regarded as internal collaborations. Papers that were written by multiple authors with multiple affiliated institutions, where the institutions are located in at least one country within and one country outside of Sub-Saharan Africa, were classified as international collaboration.

\section{Journal Information}

\section{Journal CiteScores}

CiteScores for all the journals were obtained using data from Publish or Perish (PoP) software (Harzing 2007) or Scopus Citescore report for 2021. Citescore was the choice for measuring prestige because of its simplicity, and it is an alternative to the journal impact factor. Citescore was calculated as the number of citations received in 2018 to 2020 to publications(articles, reviews, conference papers, and data papers) by a journal in the same period, divided by the number of publications in the journal within the same period[1]. We decided not to use CiteScore from journal websites because many of the journals did not have them and we could not verify the accuracy of CiteScores for journals that included them on their websites. We also decided not to use CiteScore from Scopus for all the journals because many of the journals were not indexed in Scopus (publication data was collected from Scopus, Web of Science and PubMed). The Crossref database was queried through the PoP interface to obtain the number of articles published in a journal in the years 2018 to 2020 and the number of citations received by the publications in the journal during the 2018 to 2020 period. Crossref was chosen as the source of journal citation information because of its authoritativeness, as it is used by reputable citation data sources such as Scopus and Web of Science for the collection of citation information though it is independent of the two databases. A combination of the journal title, years of publication (2018-2020) and ISSN were posed as queries on the PoP software interface. One of the limitations of the PoP is that a maximum of 1000 articles can only be retrieved per journal in a given year. Journals with more than 1000 articles in any given year were categorized as mega journals. Since $114 / 121(94.21 \%)$ of all the mega journals were captured in the 2020 Scopus CiteScore report, the CiteScores of the mega journals were obtained from Scopus 2020 Citescore report. We did not compare the CiteScores for the journals and mega journals because they were obtained using different sources.

\section{Journal OA Status and Author Processing Charge}

Conference papers, preprints, corrections, erratum, book reviews, news and preprints were excluded in the OA data collection. OA status of the retrieved publication took five values: gold, green, hybrid, bronze and closed. APCs for only gold and hybrid articles were collected because these are the OA models that 
require the payment of APCs. APCs for the articles were obtained from available publishers APC list for 2020. In cases where such lists are not available, Way Back Machine[2] was also consulted to retrieve relevant web pages on 2020 APC from the journal websites. Different pricing for different publication types and economic country categories through waivers were taken into consideration. Full texts of publications with ambiguous waivers were consulted for further information in the acknowledgement sections. An example of ambiguous APC waiver:

Page charge waivers. Manuscripts with only authors from low-and low-middle income countries and with no sources of support for page charges may qualify for a partial or full waiver of charges. Please appreciate that funds for waivers are limited. We do not grant waivers until a paper is accepted[3].

To resolve the ambiguity, we retrieved the full text of the articles with only authors from low and lowmiddle income countries (Sub-saharan Africa) to find out if the articles were funded. With the acknowledgement sections text ("Acknowledgments: Publication charges for this article were waived due to the ongoing pandemic of COVID-19."), the ambiguity was resolved.

APCs that were listed in currency other than dollars was converted using data from www.exchangerates.org.uk/. The cost of APCs was attributed to the corresponding authors' country since the convention in most journals is the payment of APCs by the corresponding author. This method is also in agreement with an earlier study where APCs costs were attributed to the corresponding authors' institution (Simard et al. 2021).

[1] https://service.elsevier.com/app/answers/detail/a_id/14880/supporthub/scopus/ /how-arecitescore-metrics-used-in-scopus\%3F/

[2] archive.org/web/

[3] (https://www.ajtmh.org/page/authorinstructions)

\section{Results}

From the result, a majority (55\%) of all Sub-Saharan African publications on COVID-19 were produced through international collaboration, which was the most popular collaboration type. In comparison, there was a negligible research synergy among the Sub-Saharan African countries as publications from intraSub-Saharan African collaboration accounted for only $3 \%$ of the papers. Single authored papers constituted $13 \%$ of all the publications, and $29 \%$ of the publications were written through national collaboration. Productivity of Sub-Saharan African countries and the contribution of countries from outside Sub-Saharan Africa to COVID-19 research from the region is presented in Table 1. As usual, South Africa, Nigeria, Kenya, Ghana, Ethiopia and Ghana are the most productive countries in Africa. Usual top collaborating countries (e.g. USA, United Kingdom, Australia, India and Canada) with Sub-Saharan Africa before the pandemic ranked among the countries that contributed most to COVID-19 research in SubSaharan Africa. 
Table 1

Productivity of Countries in and Outside Sub-Saharan Africa

Sub-Saharan African countries

\begin{tabular}{|c|c|c|c|c|c|c|}
\hline rank & country & $\begin{array}{l}\text { Documents } \\
(\%)\end{array}$ & $\begin{array}{l}\text { total link } \\
\text { strength }\end{array}$ & country & $\begin{array}{l}\text { Documents } \\
\text { (\%) }\end{array}$ & $\begin{array}{l}\text { total link } \\
\text { strength }\end{array}$ \\
\hline 1 & South Africa & $\begin{array}{l}1616 \\
(41.79)\end{array}$ & 3789 & USA & $\begin{array}{l}879 \\
(22.73)\end{array}$ & 4628 \\
\hline 2 & Nigeria & $\begin{array}{l}789 \\
(20.40)\end{array}$ & 1867 & $\begin{array}{l}\text { United } \\
\text { Kingdom }\end{array}$ & $\begin{array}{l}712 \\
(18.41)\end{array}$ & 4011 \\
\hline 3 & Kenya & $284(7.34)$ & 1246 & Australia & $272(7.03)$ & 2064 \\
\hline 4 & Ghana & 268 (6.93) & 1044 & India & $256(6.62)$ & 2241 \\
\hline 5 & Ethiopia & $261(6.75)$ & 510 & Canada & 255 (6.59) & 2045 \\
\hline 6 & Uganda & $181(4.68)$ & 806 & Italy & $232(6.00)$ & 2433 \\
\hline 7 & Cameroon & $156(4.03)$ & 535 & Germany & 218 (5.63) & 1967 \\
\hline 8 & Sudan & 125 (3.23) & 524 & China & $209(5.40)$ & 1600 \\
\hline 9 & Senegal & 104 (2.69) & 338 & France & 205 (5.30) & 1445 \\
\hline 10 & Zimbabwe & 104 (2.69) & 405 & Switzerland & $181(4.68)$ & 1598 \\
\hline 11 & Tanzania & $94(2.43)$ & 344 & Brazil & $174(4.50)$ & 1936 \\
\hline 12 & Zambia & $72(1.86)$ & 379 & Belgium & 169 (4.37) & 1053 \\
\hline 13 & $\begin{array}{l}\text { Dem. Rep. of } \\
\text { Congo }\end{array}$ & 59 (1.53) & 187 & Spain & 150 (3.88) & 1608 \\
\hline 14 & Mozambique & $58(1.50)$ & 350 & $\begin{array}{l}\text { Saudi } \\
\text { Arabia }\end{array}$ & 128 (3.31) & 937 \\
\hline 15 & Malawi & $50(1.29)$ & 250 & Netherlands & $121(3.13)$ & 1273 \\
\hline 16 & Rwanda & $49(1.27)$ & 241 & Sweden & $106(2.74)$ & 1068 \\
\hline 17 & Burkina Faso & $44(1.14)$ & 146 & Egypt & $102(2.64)$ & 1046 \\
\hline 18 & Mali & $41(1.06)$ & 139 & Japan & $91(2.35)$ & 1164 \\
\hline 19 & Benin & $36(0.93)$ & 248 & Iran & $84(2.17)$ & 974 \\
\hline 20 & Botswana & $34(0.88)$ & 155 & Turkey & $82(2.12)$ & 915 \\
\hline
\end{tabular}

Inequality in the Geographical Distribution of Journal Publishers

The 3832 publications that appeared in 1263 journals were published by 308 publishers (after removing preprints, papers in conference proceedings, erratum, corrections and news). Letters and editorials were 
included in the analysis because of their importance in COVID-19 research (Teixeira da Silva 2021). The twenty most popular journal publishers and their countries/locations are presented in Table 2. Elsevier and Springer, both publishers are located in the Netherlands, published $30.33 \%$ of all the journals and $27.69 \%$ of all the articles. Pan African Medical Journal is the most popular journal/publisher from SubSaharan Africa, and it contained $8.43 \%$ of all the articles.

Further analysis shows that only $13.4 \%$ of the publishers are in Sub-Saharan African countries. This shows that $21.14 \%$ of the articles were published in Sub-Saharan African journals. This is an indication that most of the journal articles from Sub-Saharan Africa that are indexed in the major citation databases like Scopus, Web of Science and PubMed, are not published in Sub-Saharan Africa. South Africa housed the highest number of publishers, journals and journals articles, with $8.16 \%$ of the publishers that published $10.75 \%$ of the articles in $4.03 \%$ of the journals. USA $(20.92 \%)$ and the UK $(13.73 \%)$, and India (6.21\%) house the highest number of publishers. Publishers from the Netherlands (30.72\%), UK (24.23\%) and USA (14.81\%) published the highest number of journals. Similarly, publishers from the Netherlands (28.18\%), UK (20.15\%) and USA (13.49\%) published the highest number of journals articles. 
Table 2

Journal Publishers' Location/Country

\begin{tabular}{|cllll|}
\hline & Publisher & country & $\begin{array}{l}\text { No of } \\
\text { Journals (\%) }\end{array}$ & $\begin{array}{l}\text { No of } \\
\text { papers (\%) }\end{array}$ \\
\hline 1 & Elsevier & Netherlands & $243(19.24)$ & $720(18.79)$ \\
\hline 2 & Springer & Netherlands & $140(11.09)$ & $341(8.90)$ \\
\hline 3 & Pan African Medical Journal & Kenya/Cameroun & $1(0.08)$ & $323(8.43)$ \\
\hline 4 & Informa UK & UK & $135(10.69)$ & $286(7.46)$ \\
\hline 6 & South African Medical Association & South Africa & $7(0.55)$ & $199(5.19)$ \\
\hline 5 & Wiley & USA & $91(7.21)$ & $189(4.93)$ \\
\hline 7 & Oxford Academic & UK & $37(2.93)$ & $104(2.71)$ \\
\hline 8 & AOSIS & South Africa & $17(1.35)$ & $101(2.64)$ \\
\hline 9 & Sage & Germany & $50(3.96)$ & $90(2.35)$ \\
\hline 10 & MDPI & Switzerland & $24(1.90$ & $88(2.30)$ \\
\hline 11 & British Medical Journals & United Kingdom & $12(0.95$ & $88(2.30)$ \\
\hline 12 & Frontiers & Switzerland & $20(1.58)$ & $81(2.11)$ \\
\hline 13 & $\begin{array}{l}\text { American Society of Tropical Medicine } \\
\text { and Hygiene }\end{array}$ & USA & $1(0.08)$ & $60(1.57)$ \\
\hline 14 & PLOS & USA & $4(0.32)$ & $56(1.46)$ \\
\hline 15 & Emerald & UK & $28(2.22)$ & $54(1.41)$ \\
\hline 16 & Wolter Kluwers & India & $30(2.38)$ & $53(1.38)$ \\
\hline 17 & the International Society of Global Health & UK & $1(0.08)$ & $44(1.15)$ \\
\hline 18 & Cambridge University Press & UK & $3(1.19)$ & $36(0.94)$ \\
\hline 19 & Hindawi & South Africa & $35(0.91)$ \\
\hline 20 & Academy of Science of South Africa & & $29(0.76)$ \\
\hline & ISoGH) & & & \\
\hline
\end{tabular}

Representation of Journal Publishers from Sub-Saharan Africa across Collaboration Types

The result of data on the addresses of publishers is presented in Table 3. Most of the journals (78.9\%) were published outside Sub-Saharan Africa; the proportion of the journals that were published increased for international collaboration to $91.5 \%$. The result shows that $33.3-36.3 \%$ of publications that were published through single authors and internal collaboration (national and intra-Sub-Saharan African collaboration) in Sub-Saharan Africa without contributions from international authors were published in 
Sub-Saharan African journals. In contrast, only $8.5 \%$ of the articles published in international collaborations were published in journals from Sub-Saharan Africa; this is lower than the average number of articles (21.1\%) that were published in Sub-Saharan journals from all types of collaborations. It further shows the deep underrepresentation of publications from Sub-Saharan African publishers on the global stage.

Table 3

Publishers in and outside Sub-Saharan Africa

\begin{tabular}{|llll|}
\hline Collaboration Type & \multicolumn{2}{l}{ Publishers' location } & Total \\
\cline { 2 - 3 } & Outside Sub-Saharan Africa & In Sub-Saharan Africa & \\
\hline No collaboration & $293(63.7 \%)$ & $167(36.3 \%)$ & 460 \\
\hline National collaboration & $635(62.6 \%)$ & $379(37.4 \%)$ & 1014 \\
\hline Sub-Saharan Africa & $82(66.7 \%)$ & $41(33.3 \%)$ & 123 \\
\hline International collaboration & $1817(91.5 \%)$ & $168(8.5 \%)$ & 1985 \\
\hline Total & $2827(78.9 \%)$ & $755(21.1 \%)$ & 3582 \\
\hline
\end{tabular}

Inequality in Journals' Prestige (CiteScore) across Collaboration Types and Publishers' Location

The analysis of journal prestige (measured as CiteScores) is presented for the two groups of journals(journals and mega journals in Table 4. Table 4 shows the differences between the CiteScore of journals and mega journals based on publishers' addresses (in and outside Sub-Saharan Africa). The result indicates that the CiteScore of journals published outside Sub-Saharan Africa (5.75) is five times greater than those published in the Sub-Saharan African region (1.11). In comparison, CiteScores of the mega journals published outside the Sub-Saharan African region (18.08) is twenty times greater than those published in the region (0.90). This result paints a grim picture of inequality between journals and mega journals in and outside Sub-Saharan Africa that published COVID-19 articles with authors from SubSaharan Africa. The most prestigious journals from Sub-Saharan Africa received 7.52 CiteScore, almost ten times lower than the best journal that was published outside Sub-Saharan Africa. The gulf widened with mega journals as the most prestigious mega journal from Sub-Saharan Africa received 3.80 CiteScore, 24 times lower than the CiteScore of the most prestigious mega journal from outside SubSaharan Africa.

Articles through international collaboration were published in more prestigious journals (6.80) and mega journals (16.66) than publications through single-authored papers and internal collaborations. Though mega journals are more prestigious, with a higher average CiteScore of 11.79 compared to journals with an average CiteScore of 5.01, papers through internal collaboration appeared in mega journals much lower than the average mega journal CiteScores-Sub-Saharan African collaboration-(1.85) and national collaboration-(3.96). While journal articles from Sub-Saharan Africa collaborations were published in 
journals with CiteScores (5.67) that are high compared to articles from international collaboration (6.80), the number of papers through the latter is 17 times higher than the former.

Table 4

Journals and Mega Journals' CiteScore based on Publishers' location (In or outside Sub-Saharan Africa) and Collaboration Type

\begin{tabular}{|c|c|c|c|c|c|c|c|}
\hline & & & $\mathbf{N}$ & Mean & $\begin{array}{l}\text { Std. } \\
\text { Deviation }\end{array}$ & Min & Max \\
\hline \multirow[t]{4}{*}{$\begin{array}{l}\text { Publishers' } \\
\text { Location }\end{array}$} & \multirow[t]{2}{*}{ Journals } & $\begin{array}{l}\text { Outside Sub- } \\
\text { Saharan Africa }\end{array}$ & 2268 & 5.75 & 7.74 & 0.00 & 74.57 \\
\hline & & $\begin{array}{l}\text { In Sub-Saharan } \\
\text { Africa }\end{array}$ & 432 & 1.11 & 0.94 & 0.09 & 7.52 \\
\hline & \multirow[t]{2}{*}{$\begin{array}{l}\text { Mega } \\
\text { Journals }\end{array}$} & $\begin{array}{l}\text { Outside Sub- } \\
\text { Saharan Africa }\end{array}$ & 559 & 18.08 & 28.19 & 0.21 & 91.50 \\
\hline & & $\begin{array}{l}\text { In Sub-Saharan } \\
\text { Africa }\end{array}$ & 323 & 0.90 & 0.49 & 0.80 & 3.80 \\
\hline \multirow{10}{*}{$\begin{array}{l}\text { Collaboration } \\
\text { Type }\end{array}$} & \multirow[t]{5}{*}{ Journals } & No & 412 & 2.44 & 4.37 & 0.03 & 66.85 \\
\hline & & National & 750 & 2.86 & 4.85 & 0.01 & 74.57 \\
\hline & & Sub-Saharan Africa & 81 & 5.67 & 6.93 & 0.15 & 27.45 \\
\hline & & International & 1457 & 6.80 & 8.45 & 0.00 & 74.57 \\
\hline & & Total & 2700 & 5.01 & 7.31 & 0.00 & 74.57 \\
\hline & \multirow{5}{*}{$\begin{array}{l}\text { Mega } \\
\text { Journals }\end{array}$} & No & 49 & 10.14 & 18.46 & 0.80 & 91.50 \\
\hline & & National & 265 & 3.96 & 9.52 & 0.21 & 91.50 \\
\hline & & Sub-Saharan Africa & 41 & 1.85 & 2.32 & 0.80 & 11.60 \\
\hline & & International & 527 & 16.66 & 28.61 & 0.80 & 91.50 \\
\hline & & Total & 882 & 11.79 & 23.92 & 0.21 & 91.50 \\
\hline
\end{tabular}

Inequality in Author Processing Charges Paid across Collaboration Types and Publishers' Location

Of the journal publications, 1,979 had gold or gold hybrid OA status. The Author Processing Charges and CiteScores of 1870 articles were available (i.e. the APC and CiteScores of 1422 articles in 443 journals and 448 articles in 95 mega journals. Journals published in Sub-Saharan Africa were three times cheaper (\$433.36) than those that were published outside the region. Descriptive statistics of the author processing charges paid for OA journal articles is presented in Table 5. Journals published in SubSaharan Africa averagely (\$225.73) cost seven times less than those published outside Sub-Saharan Africa (\$1557.05). Journals published outside Sub-Saharan Africa cost as much as $\$ 8536.45$, almost ten times more than the most expensive journal from a Sub-Saharan African publisher. 
Though most of the journals articles that were published through single-authorship and internal collaborations were published in journals by foreign publishers (see Table 3), it is interesting that the author processing charges paid were much lower than in international collaboration.

Table 5

Descriptive Statistics of Author Processing Charge Paid for OA Journals Articles

\begin{tabular}{|c|c|c|c|c|c|c|}
\hline & & $\mathbf{N}$ & $\begin{array}{l}\text { Mean } \\
(\$)\end{array}$ & $\begin{array}{l}\text { Std. } \\
\text { Deviation }\end{array}$ & $\begin{array}{l}\text { Min } \\
(\$)\end{array}$ & $\operatorname{Max}(\$)$ \\
\hline \multirow[t]{3}{*}{$\begin{array}{l}\text { Publishers' } \\
\text { Location }\end{array}$} & $\begin{array}{l}\text { Outside Sub-Saharan } \\
\text { Africa }\end{array}$ & 1354 & 1557.05 & 1421.71 & .00 & 8536.45 \\
\hline & In Sub-Saharan Africa & 516 & 225.73 & 176.14 & .00 & 892.30 \\
\hline & Total & 1870 & 1156.03 & 1338.41 & .00 & 8536.45 \\
\hline \multirow{5}{*}{$\begin{array}{l}\text { Collaboration } \\
\text { Types }\end{array}$} & No collaboration & 231 & 583.96 & 953.68 & .00 & 4052.00 \\
\hline & National collaboration & 594 & 537.04 & 819.94 & .00 & 5380.00 \\
\hline & Sub-Saharan Africa & 56 & 808.70 & 1457.57 & .00 & 8536.45 \\
\hline & $\begin{array}{l}\text { International } \\
\text { collaboration }\end{array}$ & 989 & 1744.74 & 1436.11 & .00 & 6000.00 \\
\hline & Total & 1870 & 1189.69 & 1351.33 & .00 & 8536.45 \\
\hline
\end{tabular}

\section{Relationship between Author Processing Charges and Journals/Mega Journals' CiteScore}

Author processing charges and mega journals' CiteScore were found to be mild positively correlated $r(489)=0.53, p<.001$. Also, author processing charges and journals CiteScore were found to be mild positively correlated $r(1377)=0.47, p<.001$. This suggests that the influence of author processing charges in predicting the CiteScore of journals in which articles were published is significant but mild. The relationship between author processing charge and journal CiteScore and mega journal CiteScore is visualized in Figure and Figure 2.

\section{Inequalities in Authorship Role during International Collaboration}

The geographical distribution of the first and last author is visualized in Figure 3 and Figure 4, respectively. Though South Africa, a country in Sub-Saharan Africa, contributed to the highest number of publications, the highest number of first authors (in the 1985 articles from international collaboration) came from the USA $(n=336,16.92 \%)$. Other countries that produced the highest number of first authors are South Africa $(n=261,13.15 \%)$, the UK $(n=251,12.65 \%)$, Nigeria $(n=168,8.46 \%)$, and India $(n=71$, $3.58 \%)$. Similarly, the USA (15.42\%), followed by South Africa (13.1\%), the UK (10.78\%), Nigeria (5.09\%) and China produced the highest number of last authors. There were only three Sub-Saharan African countries in the first ten countries with the highest number of first (South Africa, Nigeria and Ghana) and last authors (South Africa, Nigeria and Kenya) after the lists were arranged in descending order. Though 
this study focused on Sub-Saharan Africa's COVID-19 research, most of the first (56.93\%) and last authors (64.03\%) are affiliated with countries outside Sub-Saharan Africa (Figure 5).

Apart from the under-representation of authors from Sub-Saharan Africa as first and last authors, differences in journal CiteScores were also explored. The result in Table 6 shows that the journal CiteScores differ depending on the affiliation of the first and last authors with countries in or outside of Sub-Saharan Africa. Journals publications with local first authors (5.44) and last authors (6.26) received average lower CiteScores than those with foreign first authors (7.33) and last authors (7.11), respectively. Similarly, mega journals publications with local first authors (10.01) and last authors (10.96) received CiteScores half of those with foreign first authors (21.33) and last authors (19.66), respectively. 
Table 7

Differences in the CiteScores based on the location of the First and Last Authors During International Collaboration

\begin{tabular}{|c|c|c|c|c|c|c|c|}
\hline & & & $\mathbf{N}$ & Mean & $\begin{array}{l}\text { Std. } \\
\text { Deviation }\end{array}$ & Minimum & Maximum \\
\hline \multirow[t]{8}{*}{ Journals } & \multirow[t]{4}{*}{$\begin{array}{l}\text { First } \\
\text { Authorship }\end{array}$} & $\begin{array}{l}\text { Foreign } \\
\text { author }\end{array}$ & $\begin{array}{l}858 \\
(58.84 \%)\end{array}$ & 7.33 & 8.65 & .00 & 74.57 \\
\hline & & $\begin{array}{l}\text { Local } \\
\text { Author }\end{array}$ & $\begin{array}{l}387 \\
(26.54 \%)\end{array}$ & 5.44 & 7.30 & .06 & 66.85 \\
\hline & & Hybrid & $\begin{array}{l}213 \\
(14.61 \%)\end{array}$ & 7.12 & 9.27 & .00 & 66.85 \\
\hline & & Total & 1458 & 6.80 & 8.45 & .00 & 74.57 \\
\hline & \multirow[t]{4}{*}{$\begin{array}{l}\text { Last } \\
\text { Authorship }\end{array}$} & $\begin{array}{l}\text { Foreign } \\
\text { author }\end{array}$ & $\begin{array}{l}926 \\
(63.51 \%)\end{array}$ & 7.11 & 9.01 & .00 & 74.57 \\
\hline & & $\begin{array}{l}\text { Local } \\
\text { Author }\end{array}$ & $\begin{array}{l}530 \\
(36.35 \%)\end{array}$ & 6.26 & 7.36 & .00 & 66.85 \\
\hline & & Hybrid & $2(0.14 \%)$ & 4.06 & 3.02 & 1.92 & 6.19 \\
\hline & & Total & 1458 & 6.80 & 8.45 & .00 & 74.57 \\
\hline \multirow[t]{7}{*}{$\begin{array}{l}\text { Mega } \\
\text { Journals }\end{array}$} & \multirow[t]{4}{*}{$\begin{array}{l}\text { First } \\
\text { Authorship }\end{array}$} & $\begin{array}{l}\text { Foreign } \\
\text { author }\end{array}$ & $\begin{array}{l}272 \\
(51.61 \%)\end{array}$ & 21.33 & 31.08 & .80 & 91.50 \\
\hline & & $\begin{array}{l}\text { Local } \\
\text { Author }\end{array}$ & $\begin{array}{l}194 \\
(36.81 \%)\end{array}$ & 10.01 & 22.59 & .80 & 91.50 \\
\hline & & Hybrid & $\begin{array}{l}61 \\
(11.58 \%)\end{array}$ & 16.96 & 30.45 & .80 & 91.50 \\
\hline & & Total & 527 & 16.66 & 28.61 & .80 & 91.50 \\
\hline & \multirow[t]{3}{*}{$\begin{array}{l}\text { Last } \\
\text { Authorship }\end{array}$} & $\begin{array}{l}\text { Foreign } \\
\text { author }\end{array}$ & $\begin{array}{l}345 \\
(61.67 \%)\end{array}$ & 19.66 & 30.68 & .80 & 91.50 \\
\hline & & $\begin{array}{l}\text { Local } \\
\text { Author }\end{array}$ & $\begin{array}{l}182 \\
(34.54 \%)\end{array}$ & 10.96 & 23.24 & .80 & 91.50 \\
\hline & & Total & 527 & 16.66 & 28.61 & .80 & 91.50 \\
\hline
\end{tabular}

\section{Discussion}

Low Research Integration among sub-Saharan African countries

Low research integration among the Sub-Saharan Africa countries is one of the observations in the previous studies before (Asubiaro, 2019; Onyancha \& Maluleka, 2011) and after (Asubiaro \& Shaik 2021) the COVID-19 pandemic. Though international collaboration is a positive development, a biased collaboration pattern against partnership among the Sub-Saharan African countries is a concern. With 
most publications categorized as international collaboration and only 3\% intra-Sub-Saharan African collaboration, it portrays a reliance of Sub-Saharan African countries on researchers outside the continent. A three-throng collaboration pattern that includes a balanced blend of national, intra-SubSaharan African and external collaboration solutions was proffered by Onyancha (2020).

\section{Inequality in Journal Published in and Outside Sub-Saharan Africa}

Foreign publishers are dominant at the expense of local Sub-Saharan African journals as most of the COVID-19 articles with Sub-Saharan African authors were published in foreign journals. This inequality is a result of many years of epistemic bias against the knowledge that is produced in Sub-Saharan Africa as being inferior to those from the West. Only a fraction of research from Africa is indexed in the citation databases because they do not meet the set standard(Nwagwu 2010). Sub-Saharan Africa's challenges are different from other parts of the world; the same applies to the region's level of development. Researchers from this region, like other regions of the world, work based on this reality. In contrast, the major citation databases only collect data based on the world-view of the researchers from the dominant western countries, thereby favouring knowledge that is produced in the West and alienating knowledge that do not conform to this format. Perhaps, the result could have been different if a fair representation of publications from Sub-Saharan Africa were indexed in the major citation databases. Because of the bias against publications from indigenous Sub-Saharan African publishers, (Harsh et al. 2021) recommended including publications deposited on academic social networking sites because they contain some of the articles that are not captured in the conventional citation databases.

This study also shows a big inequality in the prestige of journals that are published in and outside SubSaharan Africa. This explains why even researchers that are affiliated with institutions in Sub-Saharan Africa published more than $60 \%$ of their journal articles in foreign journals, despite the cheaper author processing charges of journals that are from publishers in Sub-Saharan Africa. These journals are in a conundrum because while the Sub-Saharan African journals do not have global appeal because they focus on Sub-Saharan African-related themes, researchers from the region want global visibility for their works. Sub-saharan Africa has an author processing fee deficit because they pay more author processing fees than they receive. Publishers in Sub-Saharan Africa pay more author processing fees than the amount received by the publishers in the region. Therefore, author processing fees paid by researchers in Sub-Saharan Africa mostly go to publishers in the UK, Europe and North America.

Foreign authors hardly publish in Sub-Saharan African journals even when collaborating with researchers from Sub-Saharan African countries. Though the journals that are published in Sub-Saharan Africa are much cheaper in author processing charges, they are also not attractive because they rank low in prestige. Hence, the journals are hard to sell because there are alternatives that may offer higher prestige for the same or lower price. Secondly, journals in Sub-Saharan Africa hardly engage in aggressive marketing to attract prestigious and relevant articles. Besides, journals in Sub-Saharan do not enjoy the robust infrastructure that is available to journals outside the region; these infrastructures support easy retrieval, fast review, easy dissemination and visibility of manuscripts. For instance, authors prefer to 
publish in foreign journals with an easily trackable and fast review process and the prospect of higher visibility for the accepted manuscripts.

\section{Inequality in Collaboration Patterns}

It is very interesting that most of the publications were produced through international collaboration. By the way, the argument in this study is not against international collaboration in healthcare in SubSaharan Africa because we regard international collaboration as a level of development in science, and previous studies have shown it is beneficial to Sub-Saharan Africa (Frieden \& Damon 2015; Tesema et al. 2020). However, we argue against the dominance of international collaboration and recommend an increase in synergy among the Sub-Saharan African countries for a research partnership. On the one hand, this imbalance could be regarded as epistemic wrong from the pose/positionality perspective. Epistemic wrongs from pose/positionality are the practices associated with the groups involved in the knowledge production process (Bhakuni \& Abimbola 2021). Sub-Saharan Africa, as a social entity in the research world, has the mandate to create its own research agenda. Right now, there is no research framework or infrastructure to facilitate collaboration and synergy for health research between SubSaharan African countries by stakeholders in the region. The progress that is recorded, if any, is from the auto-pilot mechanism that has been in place for pan-Sub-Saharan African research integration from time immemorial. Though each country in the region may have its own research agenda/framework, pan-SubSaharan Africa research will strengthen the scientific position of the individual countries and the region as a unit in the global scientific system.

On the other hand, the inclination towards international collaboration with countries outside Sub-Saharan countries at the expense of internal Sub-Saharan African collaboration is an epistemic wrong that could also be associated with gaze/audience. Epistemic wrongs from gaze are the practices that stifle the voices of a marginalized social entity in a research community by the audience (Bhakuni \& Abimbola 2021). In this case, authors from Sub-Saharan Africa prefer to collaborate with researchers outside Sub-

Saharan Africa because it is an opportunity to associate with the dominant group in global health research whose research is considered credible to the global audience. Authors from Sub-Saharan Africa do this to benefit from the "credibility excess" that researchers from the developed countries enjoy and alleviate their own "credibility deficiency" (Bhakuni \& Abimbola 2021).

\section{Inequality in Authorship Positions during International Collaboration}

Though the study focused on Sub-Saharan Africa's COVID-19 research, foreign authors dominated the first and last author positions. This is a depiction of inequality against authors from Sub-Saharan African countries. This result corroborates earlier studies that reported authors from Ghana, a Sub-Saharan African country, participate in international collaboration in fringe roles like data collection or fieldwork(Owusu-Nimo \& Boshoff 2017). Studies have reported that power dynamics shape how authors from low and middle-income countries, like the Sub-Saharan African countries, are represented when they collaborate with authors from high-income countries. For instance, (Hedt-Gauthier et al. 2019) noted that 
authors from Africa were less likely to feature in the first and last author positions when they engage in collaboration with foreign authors.

The power dynamics between authors in Sub-saharan Africa and high-income countries stem from practices that are associated with epistemic wrongs of pose or positionality and gaze or audience. Epistemic wrongs that are associated with pose or positionality also occur when dominant groups in science or "knowledge practices (in this case, authorship) limit the extent to which marginalized groups have ownership of knowledge production and sensemaking" (Bhakuni \& Abimbola 2021). The power dynamics that relegate Sub-Saharan African authors from the lead authorship position in studies about Sub-Saharan Africa is limiting the extent to which they own knowledge from their locality. Authorship position mostly reflect the sensemaking or intellectual contribution of authors. It is perceived that the lead and last authorship positions in research are the most prestigious because they mostly theorize, interpret data and lead other researchers on the authorship list, while others that are stuck in the middle may not have contributed in the same magnitude. The practice of not recognizing local authors in the lead/last authorship position downplays the sensemaking ability of the local authors who may have a better understanding of the problems because they have the first-hand experience and therefore be in the best position to perform the duties of the first and last author.

The study is supported by earlier studies that researchers from developing countries like Sub-Saharan Africa are likely to be relegated to fringe roles even as local researchers or hosts to foreign authors and are accorded "credibility deficit". Despite the knowledge of the local researcher about the scientific and social context, they are only assigned the role of data collector. On the other hand, the foreign researcher enjoys "credibility excess" and is saddled with the role of theorizing and analyzing the data. Local SubSaharan African authors may suffer credibility deficits, as suggested by the authorship analysis in this study because foreign authors dominate the first and last authorship position in a study that focused on Sub-Saharan Africa's COVID-19 research (Bhakuni \& Abimbola 2021).

\section{Conclusion And Recommendations}

This study focused on studying inequality in COVID-19 research from Sub-Saharan Africa. The study found that international collaboration accounted for the majority of the studies. While this is a good development, we concluded this is unhealthy after comparing the inclination towards international partnership with the negligible synergy between Sub-Saharan African. This study also found the dominance of advanced countries in prominent authorship positions (first and last author). Similarly, publications through internal Sub-Saharan African collaboration were much less prestigious than the publications from international collaboration. This study also found that Sub-Saharan African researchers mostly publish in journals outside the region, though the journals that are published in the region are much cheaper but less prestigious.

This study recommends a scientific partnership between Sub-Saharan Africa and the developed countries that eradicates the imbalances between researchers from developed countries and the region. There is a 
need for a more equitable partnership that encourages publishing important research in journals that are published in Sub-Sharan Africa. One of the selling points of the journals from Sub-Saharan Africa is they are very cheap, they could become more prestigious if more important articles are published in them. The inclusion of local researchers from Africa as lead authors and not as "ordinary field agents" especially in studies about or in Sub-Saharan Africa is important for creating equity.

There is a need for research stakeholders in Sub-Saharan Africa to design a roadmap for a stronger research partnership between Sub-Saharan African countries. A stronger research agenda for SubSaharan Africa that will strengthen its research by developing a citation index is also recommended. The African Citation Index that was started by the Council for the Development of Social Research in Africa (CODESRIA) which is now defunct comes handy in this regard.

\section{Limitations of the Study}

One of the limitations of the study is that the effect of the number of authors on authorship position was not normalized. For instance, the last authors in two-authored papers may be nominal since the second author is automatically the last author. Secondly, we did not collect data before the COVID-19 pandemic so that a comparative study could be made; therefore, this study is exploratory.

\section{Declarations}

\section{Availability of data and materials}

The datasets generated and/or analyzed during the current study are available in the Mendeley repository, through doi: $10.17632 / 6 f g j x k v 28 d .3$

\section{Competing interests}

The authors reported no potential competing interests.

\section{Funding}

This work is supported by the Social Science and Humanities Research Council of Canada (SSHRC) Insight Grant \#435-2019-0019, 2019-2022.

\section{Acknowledgements}

We thank our anonymous reviewers for their thoughtful comments that helped strengthen this article

\section{Authors' Contribution}

TVA conceived the research idea, collected and analyzed data, and wrote the manuscript. 


\section{References}

Asubiaro, T. (2019). 'How Collaboration Type, Publication Place, Funding and Author's role affect Citations Received by Publications from Africa? A Bibliometric study of LIS research from 1996 to 2015', Scientometrics, 120/3: 1261-87. DOI: https://doi.org/10.1007/s11192-019-03157-1

Asubiaro, T., \& Shaik, H. (2021). 'Sub-Saharan African Countries' COVID-19 Research: An analysis of the External and Internal Contributions, Collaboration Patterns and Funding Sources',.

Asubiaro, T. V., \& Badmus, O. M. (2020). 'Collaboration clusters, interdisciplinarity, scope and subject classification of library and information science research from Africa: An analysis of Web of Science publications from 1996 to 2015', Journal of Librarianship and Information Science, 52/4: 1169-85. DOI: $10.1177 / 0961000620907958$

Bendana, C. (2019). 'African research projects are failing because funding agencies can't match donor money', Science / AAAS. DOI: doi:10.1126/science.aax6796

Bendels, M. H. K., Wanke, E., Schöffel, N., Bauer, J., Quarcoo, D., \& Groneberg, D. A. (2017). 'Gender equality in academic research on epilepsy-a study on scientific authorships', Epilepsia, 58/10: 1794-802. DOI: 10.1111/epi.13873

Bhakuni, H., \& Abimbola, S. (2021). 'Epistemic injustice in academic global health', The Lancet Global Health, 9/10: e1465-70. Elsevier. DOI: 10.1016/S2214-109X(21)00301-6

Boshoff, N. (2009). 'Neo-colonialism and research collaboration in Central Africa', Scientometrics, 81/2: 413. DOI: $10.1007 / \mathrm{s} 11192-008-2211-8$

Broderick, N. A., \& Casadevall, A. (2019). 'Gender inequalities among authors who contributed equally', eLife, 8. DOI: 10.7554/eLife.36399

Confraria, H., \& Godinho, M. M. (2015). 'The impact of African science: a bibliometric analysis', Scientometrics, 102/2: 1241-68. DOI: 10.1007/s11192-014-1463-8

Cui, R., Ding, H., \& Zhu, F. (2021). 'Gender Inequality in Research Productivity During the COVID-19 Pandemic', Manufacturing \& Service Operations Management, msom.2021.0991. DOI:

$10.1287 /$ msom. 2021.0991

Frieden, T. R., \& Damon, I. K. (2015). 'Ebola in West Africa-CDC's Role in Epidemic Detection, Control, and Prevention', Emerging Infectious Diseases, 21/11: 1897-905. DOI: 10.3201/eid2111.150949

Harsh, M., Bal, R., Weryha, A., Whatley, J., Onu, C. C., \& Negro, L. M. (2021). 'Mapping computer science research in Africa: using academic networking sites for assessing research activity', Scientometrics, 126/1: 305-34. DOI: 10.1007/s11192-020-03727-8 
Harzing, A.W. (2007). Publish or Perish.

Hedt-Gauthier, B. L., Jeufack, H. M., Neufeld, N. H., Alem, A., Sauer, S., Odhiambo, J., Boum, Y., et al. (2019). 'Stuck in the middle: a systematic review of authorship in collaborative health research in Africa, 20142016', BMJ Global Health, 4/5: e001853. DOI: 10.1136/bmjgh-2019-001853

Holman, L., Stuart-Fox, D., \& Hauser, C. E. (2018). 'The gender gap in science: How long until women are equally represented?', PLOS Biology, 16/4: e2004956. Public Library of Science. DOI:

10.1371/journal.pbio.2004956

Huang, J., Gates, A. J., Sinatra, R., \& Barabási, A.-L. (2020). 'Historical comparison of gender inequality in scientific careers across countries and disciplines', Proceedings of the National Academy of Sciences, 117/9: 4609-16. National Academy of Sciences. DOI: 10.1073/pnas.1914221117

King, M. M., \& Frederickson, M. E. (2021). 'The Pandemic Penalty: The Gendered Effects of COVID-19 on Scientific Productivity', Socius, 7: 23780231211006976. SAGE Publications. DOI:

$10.1177 / 23780231211006977$

Laakso, M., Welling, P., Bukvova, H., Nyman, L., Björk, B.-C., \& Hedlund, T. (2011). 'The Development of Open Access Journal Publishing from 1993 to 2009', PLOS ONE, 6/6: e20961. Public Library of Science. DOI: 10.1371/journal.pone.0020961

LaLonde, K. (Ed.). (2020). COVID-19 Literature Searching. Medical Library Association.

Muric, G., Lerman, K., \& Ferrara, E. (2021). 'Gender Disparity in the Authorship of Biomedical Research Publications During the COVID-19 Pandemic: Retrospective Observational Study', Journal of Medical Internet Research, 23/4: e25379. DOI: 10.2196/25379

Nwagwu, W. E. (2010). 'Cybernating the academe: Centralized scholarly ranking and visibility of scholars in the developing world', Journal of Information Science, 36/2: 228-41. SAGE Publications Ltd. DOI:

$10.1177 / 0165551509358482$

Onyancha, O. B. (2020). 'Regional and international research collaboration and citation impact in selected sub-Saharan African countries in the period 2000 to 2019', Global Knowledge, Memory and Communication, ahead-of-print/ahead-of-print. DOI: 10.1108/GKMC-04-2020-0039

Onyancha, O. B., \& Maluleka, J. R. (2011). 'Knowledge production through collaborative research in subSaharan Africa: how much do countries contribute to each other's knowledge output and citation impact?', Scientometrics, 87/2: 315-36. DOI: 10.1007/s11192-010-0330-5

Owusu-Nimo, F., \& Boshoff, N. (2017). 'Research collaboration in Ghana: patterns, motives and roles', Scientometrics, 110/3: 1099-121. DOI: 10.1007/s11192-016-2221-X 
Parlak, S., Celebi Cakiroglu, O., \& Oksuz Gul, F. (2021). 'Gender roles during COVID-19 pandemic: The experiences of Turkish female academics', Gender, Work \& Organization, 28/S2: 461-83. DOI: 10.1111 /gwao. 12655

Philipp, T., Botz, G., Kita, J.-C., Richards, P., Sänger, A., Siegert, O., \& Reumaux, M. (2021). Open Access Monitoring: Guidelines and Recommendations for Research Organisations and Funders., pp. 1-22. Rue de la Science 14, 1040 Brussels, Belgium: Science Europe AISBL. Retrieved September 23, 2021, from <https://www.scienceeurope.org/media/cqllmhzo/se-oamonitoring-briefing-paper-2021.pdf>

Pinho-Gomes, A.-C., Peters, S., Thompson, K., Hockham, C., Ripullone, K., Woodward, M., \& Carcel, C. (2020). 'Where are the women? Gender inequalities in COVID-19 research authorship', BMJ Global Health, 5/7: e002922. BMJ Specialist Journals. DOI: 10.1136/bmjgh-2020-002922

Pouris, A., \& Ho, Y.-S. (2014). 'Research emphasis and collaboration in Africa', Scientometrics, 98/3: 2169-84. DOI: $10.1007 / \mathrm{s} 11192-013-1156-8$

Simard, M.-A., Asubiaro, T., \& Mongeon, P. (2021). 'The burden of article processing charges on Canadian universities', Proceedings of the Annual Conference of CAIS / Actes du congrès annuel de I'ACSI. DOI: $10.29173 /$ cais 1224

Staniscuaski, F., Kmetzsch, L., Soletti, R. C., Reichert, F., Zandonà, E., Ludwig, Z. M. C., Lima, E. F., et al. (2021). 'Gender, Race and Parenthood Impact Academic Productivity During the COVID-19 Pandemic: From Survey to Action', Frontiers in Psychology, 12: 1640. DOI: 10.3389/fpsyg.2021.663252

Teixeira da Silva, J. A. (2021). 'The importance for journals to publish commentaries and letters to the editor in the age of COVID-19', International Journal Of Community Medicine And Public Health, 8/7: 3725. DOI: $10.18203 / 2394-6040 . i j c m p h 20212637$

Tesema, A. G., Ajisegiri, W. S., Abimbola, S., Balane, C., Kengne, A. P., Shiferaw, F., Dangou, J.-M., et al. (2020). 'How well are non-communicable disease services being integrated into primary health care in Africa: A review of progress against World Health Organization's African regional targets', PLOS ONE, 15/10: e0240984. Public Library of Science. DOI: 10.1371/journal.pone.0240984

\section{Figures}




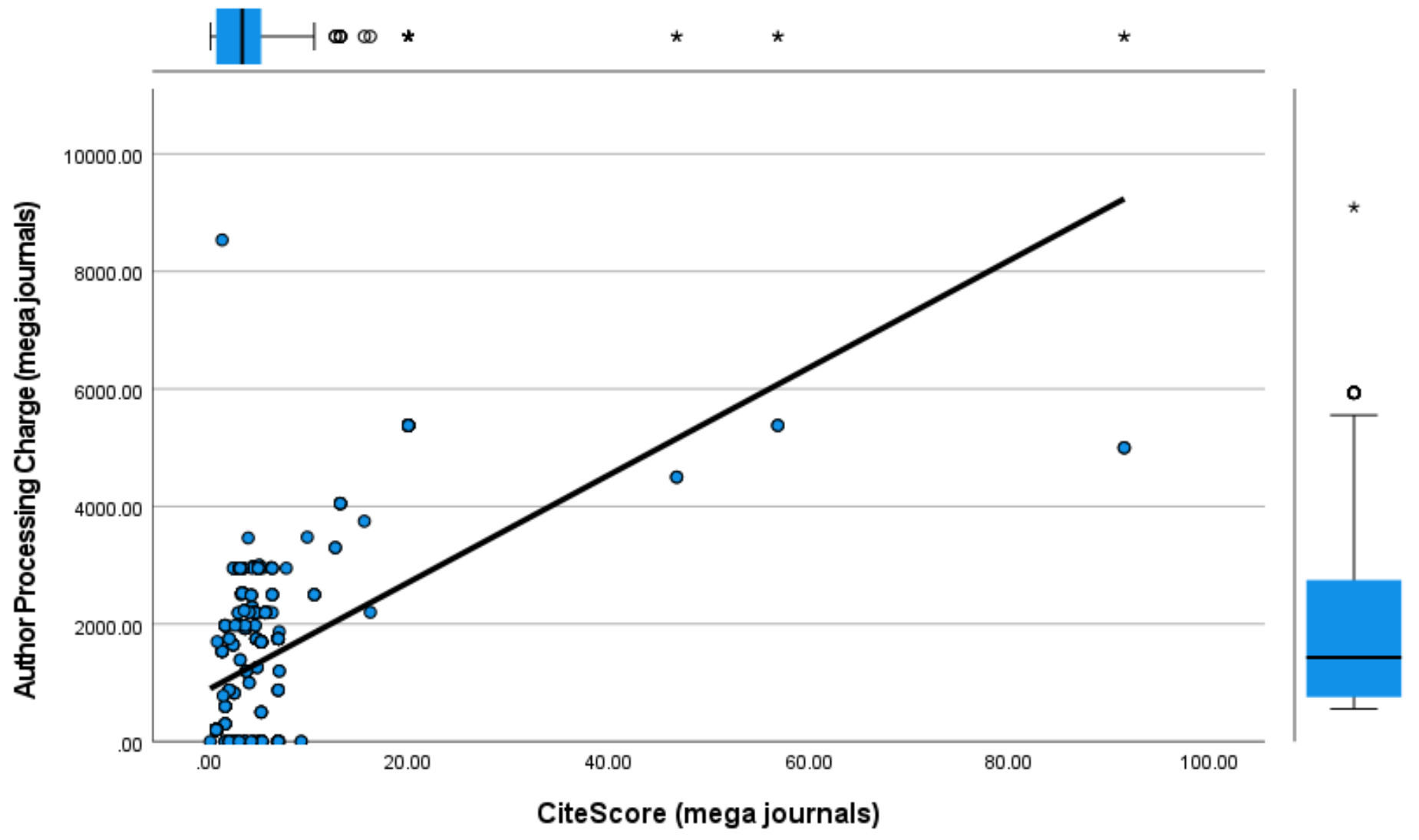

Figure 1

Author Processing Charge Vs Mega Journals' CiteScore 


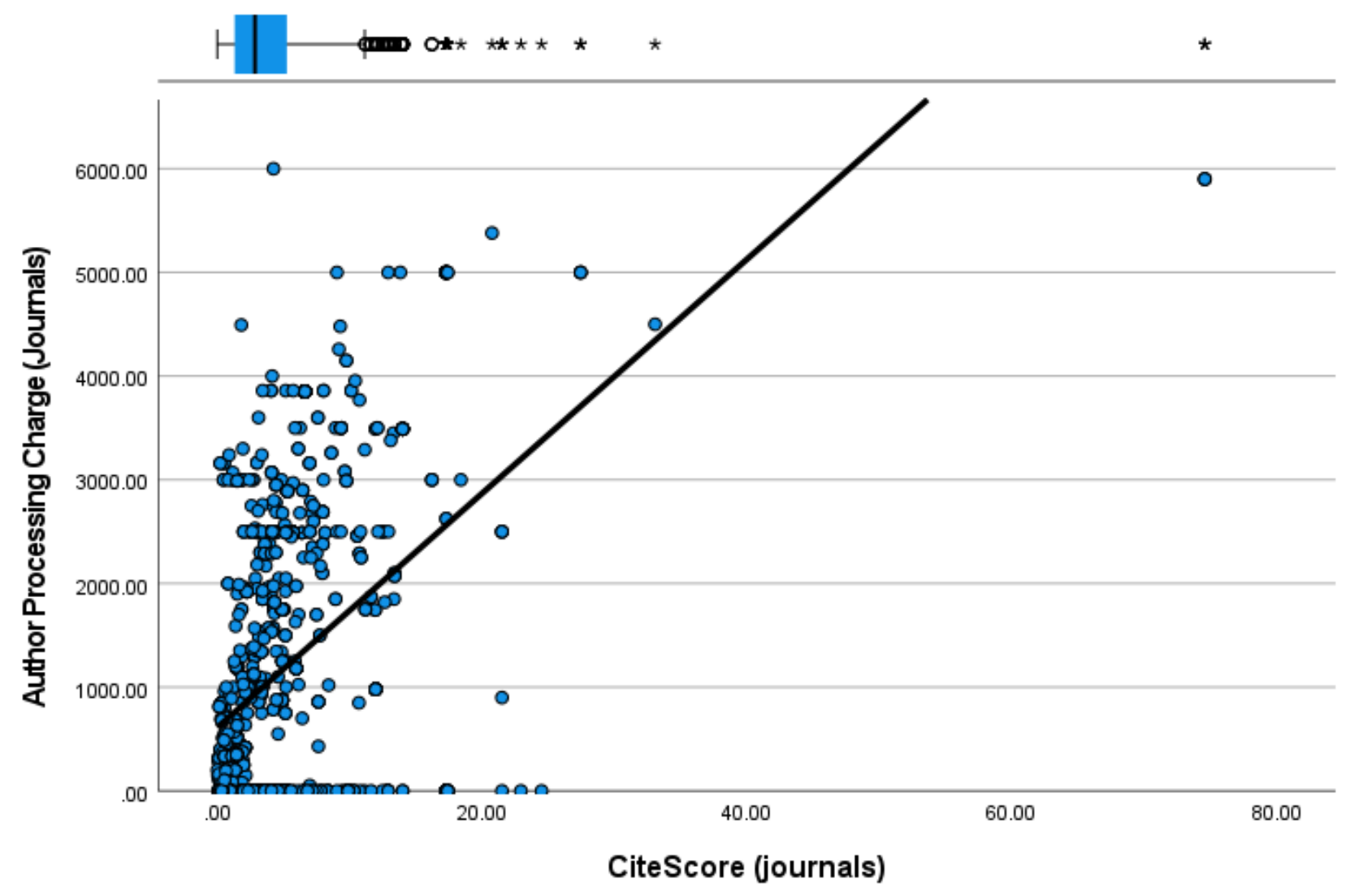

Figure 2

Author Processing Charge Vs Journals' CiteScore

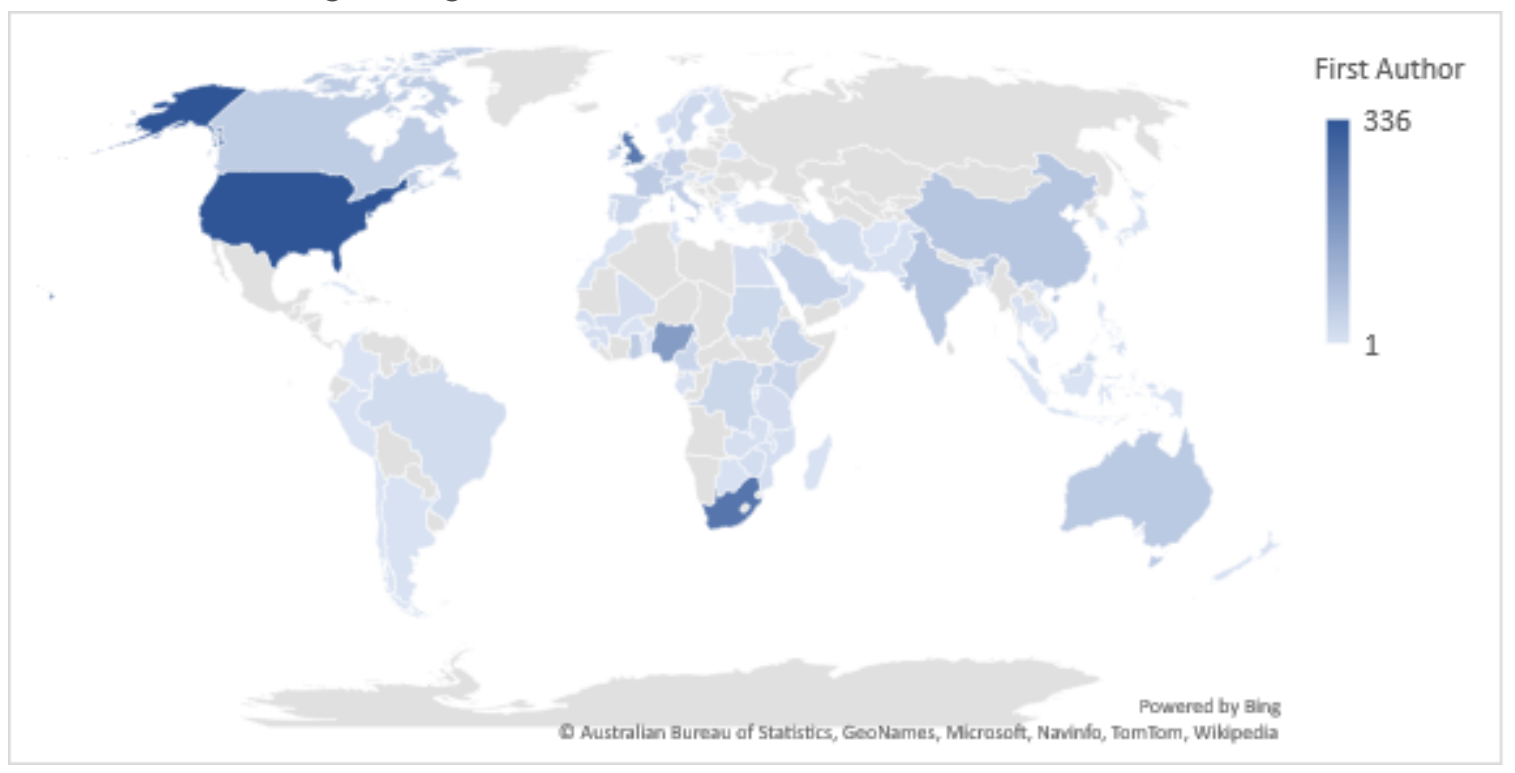

Figure 3

Geographical Distribution of First Authors in International Collaboration 


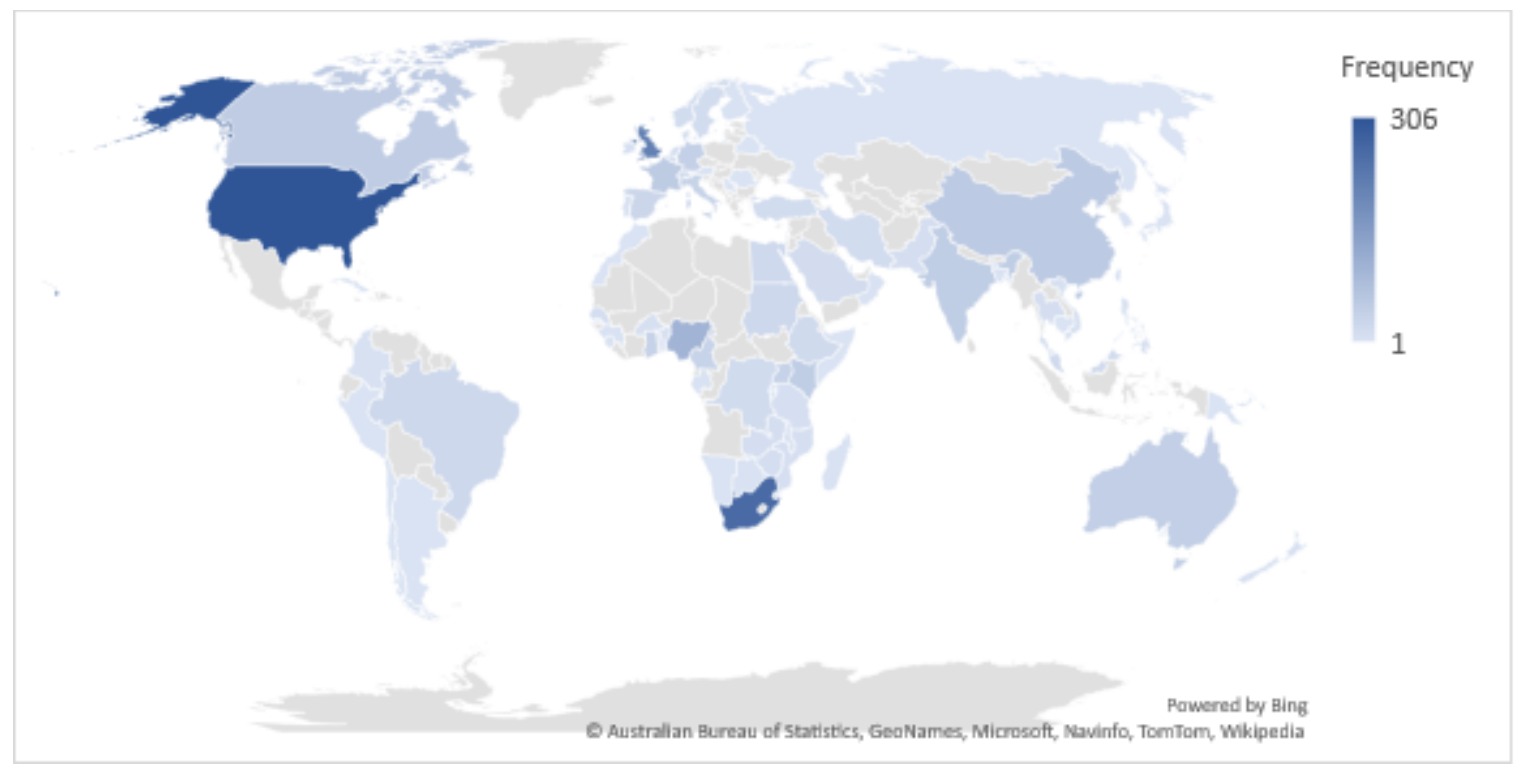

\section{Figure 4}

Geographical Distribution of Last Authors in International Collaboration

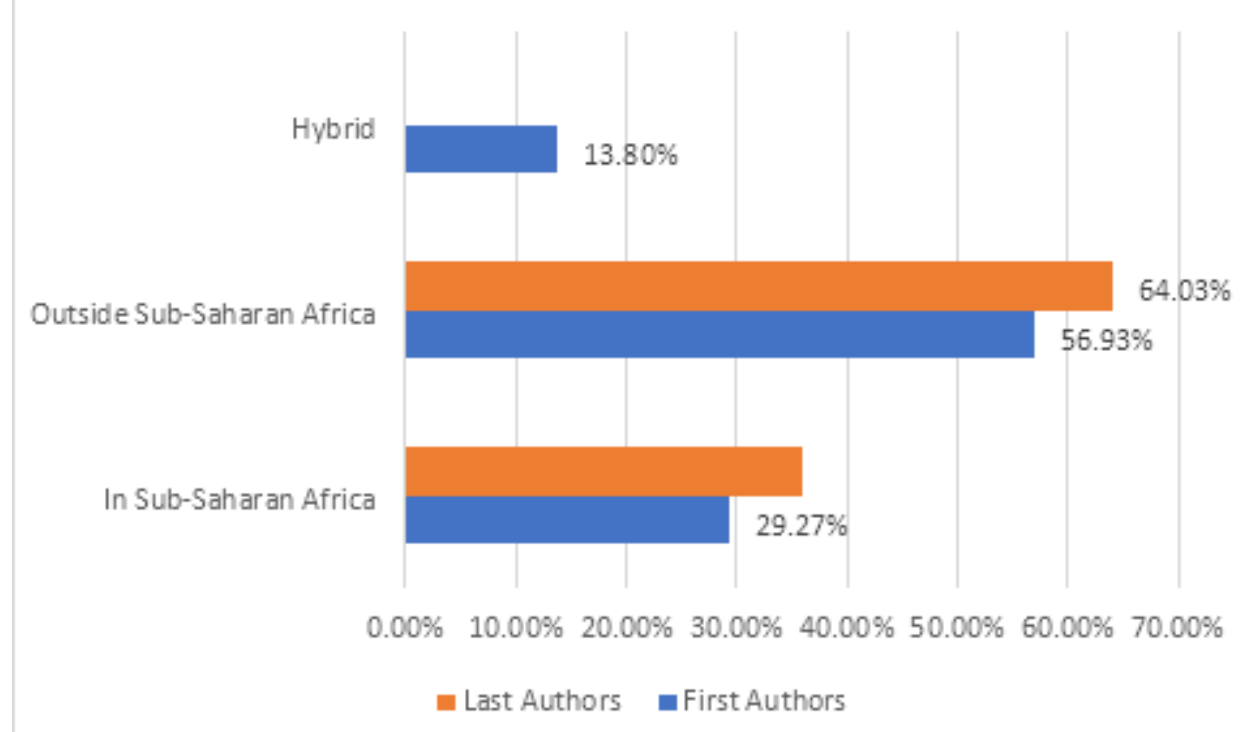

\section{Figure 5}

First and Last Authors affiliation with Countries in and Outside Sub-Saharan Africa 